\title{
Observed effects of a geomagnetic storm on an RTK positioning network at high latitudes
}

\author{
Knut Stanley Jacobsen* and Sebastian Schäfer \\ Norwegian Mapping Authority, Hønefoss, Norway \\ *corresponding author: e-mail: jacokn@statkart.no
}

Received 16 March 2012 / Accepted 8 August 2012

\begin{abstract}
At high latitudes, above $60^{\circ} \mathrm{N}$, in the vicinity of the auroral oval, the ionosphere frequently experiences disturbed conditions that impact GNSS-based services. The Norwegian Mapping Authority (NMA) is operating a national real-time kinematic (RTK) positioning network and an ionosphere monitoring software. This paper presents the ionospheric observations during a geomagnetic storm, and the observed consequences for the positioning service. Significant disruptions that can be clearly related to the ionospheric disturbances were observed. They tend to occur in roughly longitudinal bands, which is expected for disturbances caused by the particle and energy precipitation in the auroral oval. The position error is found to increase exponentially with increasing rate of TEC index (ROTI). The disturbances are compared to auroral electrojet measurements and results from an operational auroral oval forecasting model. The disturbances are found to be strongly related to auroral electrojet currents.
\end{abstract}

Key words. space weather - positioning system - ionosphere (auroral) - storm - Coronal Mass Ejection (CME)

\section{Introduction}

Satellite-based navigation and positioning systems are widely used throughout the world. It is well known that these systems are vulnerable to space weather events, but current monitoring and prediction services do not provide information about exactly when and where these systems are or will be disturbed by such events or the magnitude of the disturbance that will be experienced by users. As part of an effort toward investigating this and establishing such services, we are studying the effects of space weather events on the national positioning service CPOS, which is operated by the Norwegian Mapping Authority (NMA).

Geomagnetic storms are caused by the interaction of the Earth's magnetic field with the plasma and magnetic fields of the solar wind. The variations in the properties of the solar wind are in turn linked to events on the Sun. This paper does not present the theoretical background of space weather and its effects, which has been covered by many other authors (e.g., Buonsanto 1999; Eastwood 2008; Watermann et al. 2009; Singh et al. 2010; Hernandez-Pajares et al. 2011; Gonzalez et al. 2011). The main effect that is relevant for GNSS systems at high latitudes is the response of the auroral oval to the space weather events. Generally, dense and/or fast-moving plasma clouds in the solar wind transfer a large amount of energy and particles to the region in space dominated by Earth's magnetic field, the magnetosphere. The efficiency of the transfer depends strongly upon the orientation of the magnetic field of the solar wind, being strongest for a southward-pointing magnetic field. Through processes in the magnetosphere, some of the energy and particles eventually precipitate into the ionosphere. This precipitation takes place mostly in a region called the auroral zone, and the resulting structuring of the ionosphere plasma disturbs the GNSS signals passing through it.

Presented in this paper are the effects of a geomagnetic storm that took place on the 24-25th October 2011. It was caused by a coronal mass ejection (CME) that was propelled in our direction by the eruption of an unstable magnetic filament around 0100 UT on 22nd October. The CME was particularly geoeffective because it contained a large region of southward-pointing magnetic fields.

Sections 2.1 and 2.2 introduce the positioning service and the ionosphere monitoring program. The observations are presented in Sect. 3 and discussed in Sect. 4.

\section{Main data sources}

\subsection{CPOS}

CPOS is a network real-time kinematic (RTK; Frodge et al. 1994; Rizos 2003) positioning service, operated by the NMA. Based on the data collected from NMA's network of permanent GNSS stations, it provides real-time positioning at cm-level accuracy for users in Norway. By "real time", we mean that from the time when measurements are taken by our receivers to the time when corrections are sent to the users, less than one second passes. The RTK software used is GPSNet version 2.74 from Trimble, processing double-differenced GPS and GLONASS measurements. One measure of the status of the network solution is whether the network has a fixed solution for the phase ambiguities for each satellite at each station. A satellite is "Solved", if it gets a fixed solution. If a satellite is solved, that means, the correction data for this satellite is available. To be broadcasted, these corrections need simultaneous observations to at least five satellites from at least three stations. If more stations are available, the correction set will be calculated using up to six stations. If no satellites are "Solved" at a station, it does not contribute anything to the network solution.

Figure 1 shows the location of the GNSS stations. The maximum separation between adjacent stations is $70 \mathrm{~km}$, while a 
typical interstation distance is around $50-60 \mathrm{~km}$. The receivers are of dual frequency, capable of tracking GPS and GLONASS, and samples at $1 \mathrm{~Hz}$. The northernmost part of Norway, around $70^{\circ} \mathrm{N}$, lies beneath the nighttime auroral oval during normal conditions. During geomagnetic storms, the auroral oval expands southward and may reach the middle or even southern parts of Norway.

Some of the results in this paper are sorted into three regions; Northern Norway $\left(67-72^{\circ} \mathrm{N}\right)$, middle Norway (62$\left.67^{\circ} \mathrm{N}\right)$ and Southern Norway $\left(57-62^{\circ} \mathrm{N}\right)$. The difference between the universal time and the magnetic local time (UTMLT) is in the range 2.6-3.8 for the northern region, 3.6-4.3 for the middle region and 3.8-4.3 for the southern region.

To monitor the performance of the CPOS service, a monitoring receiver is set up at the Hønefoss station, at approximately $60.14^{\circ}$ North, $10.25^{\circ}$ East. This receiver acts as a CPOS user and continuously logs its calculated position.

\subsection{RTIM}

The Real-Time Ionosphere Monitor (RTIM) program receives data from the GNSS network and estimates the state of the ionosphere. Currently, only GPS data are used. The ionospheric parameters that are used in this paper are:

- The Vertical Total Electron Content (VTEC). This is produced by Kriging interpolation of the VTEC values calculated for each ionospheric pierce point (IPP), using a single layer ionosphere model. The single layer model is the assumption that the entire TEC of the ionosphere is located in a thin spherical shell. For the calculations performed here, the altitude at which this shell is located is $350 \mathrm{~km}$. This altitude is the same as that used by the GNSS augmentation systems WAAS (Wide Area Augmentation System) and EGNOS (European Geostationary Navigation Overlay Service). As a simple test of the sensitivity of the algorithms to the shell altitude, we have processed some datasets using also altitudes of 250 and $450 \mathrm{~km}$. For features as large as those presented in this paper, there is no significant difference.

- The rate of TEC index (ROTI; Pi et al. 1997). This is calculated independently for each IPP, and then further processed by interpolation and averaging to produce various data products. It characterizes small-scale and/or rapid variations of TEC, and is strongly related to scintillation (Basu et al. 1999). The scale size of the fluctuations characterized by the ROTI depends on the plasma flow velocity relative to the IPP, and the sampling rate of the GNSS receiver. For a $1 \mathrm{~Hz}$ receiver and typical high-latitude velocities of 0.1 to $1 \mathrm{~km} \mathrm{~s}^{-1}$, the scale size is approximately 0.1 to $1 \mathrm{~km}$.

- The phase scintillation index $\sigma_{\phi}$ (Kintner et al. 2007; Yeh $\&$ Liu 1982). The $\sigma_{\phi}$ data used in this paper was collected by a scintillation receiver located in Hønefoss. In the auroral zone, phase scintillation is much more common than amplitude scintillation (Tiwari et al. 2010; Aquino et al. 2005; Skone et al. 2009).

\section{Observations}

In the evening of 24th October 2011, a CME impacted the Earth's magnetosphere. Figure 2 shows measurements of the
CME in the solar wind in the top two panels, and measurements of the geomagnetic disturbances in the bottom panel. The solar wind data has been timeshifted to correspond to the arrival of the resulting effects in the ionosphere of the Earth. A summary of the time series is as follows:

- At 18:45 UT, there is a very sharp increase in flow pressure accompanied by a turbulent magnetic field. This marks the start of the CME. The value of the $K p$ index rises from a very low level, $K p=1$, to the minor geomagnetic storm level, $K p=5$, for the 18-21 UT interval.

- At $22 \mathrm{UT}$, the magnetic field Z-component changes to a steady negative value of some nT. The energy transfer, by reconnection, from the solar wind to the Earth system is most effective for a negative $Z$-component.

- At 23 UT, the magnetic field Z-component changes to a steady negative value of -10 to $-20 \mathrm{nT}$. For the $21-$ 24 UT interval, the $K p$ index is at a strong geomagnetic storm level.

- At 01:30 UT the next day, the flow pressure decreases and the magnetic field $Z$-component starts to fluctuate around zero. In the following hours, the $K p$ index gradually decreases.

- The 09-12 UT interval is the first interval in which the $K p$ index is below the minor geomagnetic storm level.

An overview of the disruptions of the CPOS service is shown in Figure 3. The top panel covers Northern Norway $\left(67-72^{\circ} \mathrm{N}\right)$, the middle panel covers middle Norway $\left(62-67^{\circ} \mathrm{N}\right)$ and the bottom panel covers Southern Norway $\left(57-62^{\circ} \mathrm{N}\right)$. Each panel shows the number of stations in that latitude range that are unable to compute a fixed solution for a certain percentage of the currently visible satellites. The blue line indicates mild to moderate disruptions, while the red line indicates severe to total disruptions. The spikes at 14:30 on the 24th and 03:30 on the 25th are caused by technical issues, not by the geomagnetic storm. A summary of the time series is as follows:

- At 18:45 UT, the first interval of disruption is seen in the northern region. At this time there are no disruptions at the other latitudes.

- At 20 UT, disruptions in the northern region stop.

- At 21 UT, the second interval of disruption is seen in both the northern and middle regions, causing moderate disturbances in more than half of the regions.

- At 22:30 UT, the disruptions in the northern region disappear, while for the first time disruptions appear in the southern region. The disruptions reappear in the northern region $30 \mathrm{~min}$ later. At this time, the disruptions in the north are much more severe, and the disruptions in the middle are more severe. For the next $2 \mathrm{~h}$, the entire northern region is disrupted, and more than half is so severely disrupted as to be practically disabled. At the same time, the middle region is severely disrupted and the southern region is mildly to moderately disrupted.

- At 01 UT on the 25th October, the disruptions in the North suddenly drop from almost complete to just affecting small parts of the network. At the same time, the disruptions in the middle take a short break before coming back stronger than before. Disruptions in the southern region increase in severity.

- At 03 UT, disruptions in the middle and southern regions stop.

- At 05 UT, disruptions in the northern region stop. 
K.S. Jacobsen and S. Schäfer: Geomagnetic storm effects on an RTK network

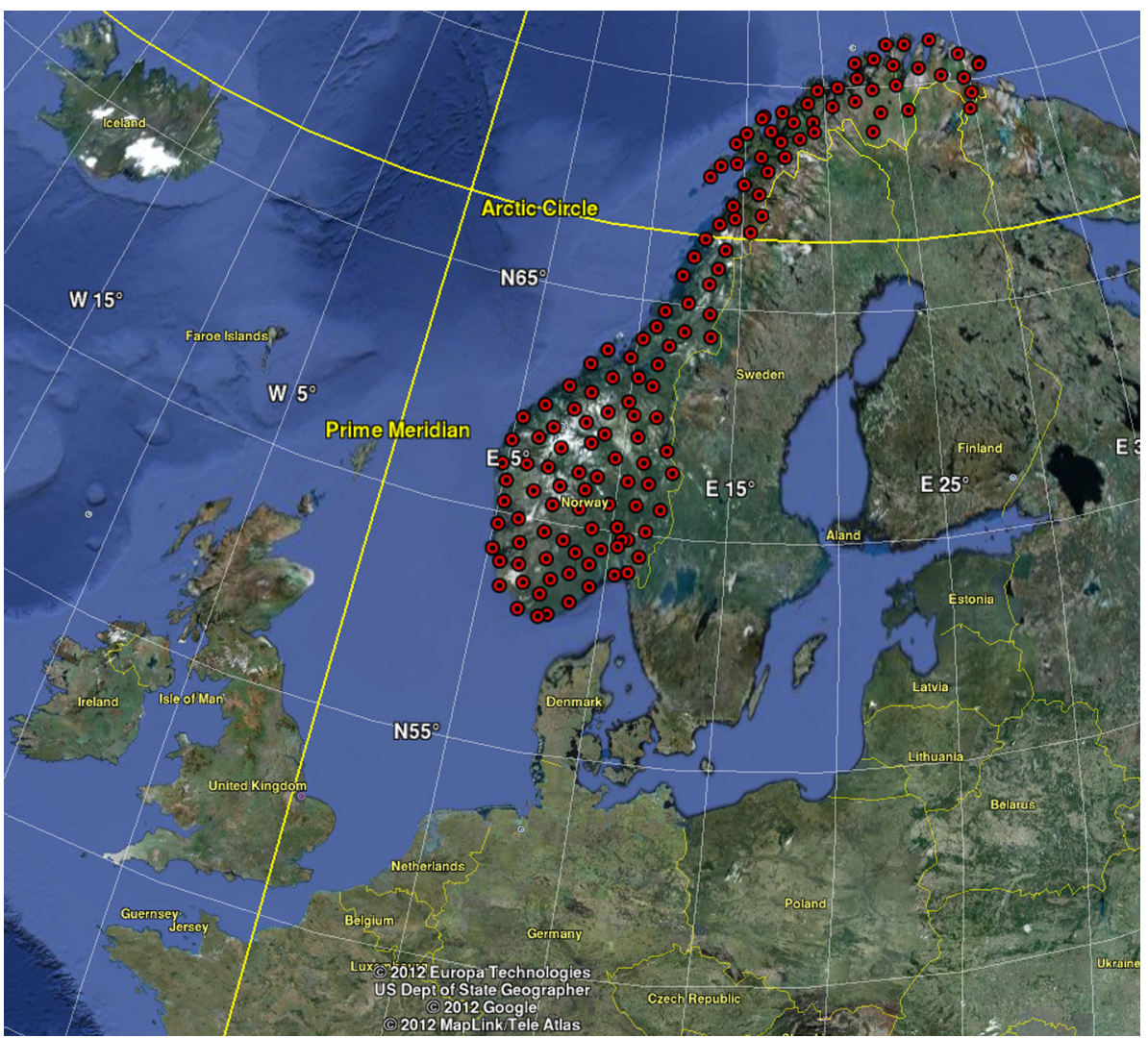

Fig. 1. Permanent NMA GNSS stations in mainland Norway.
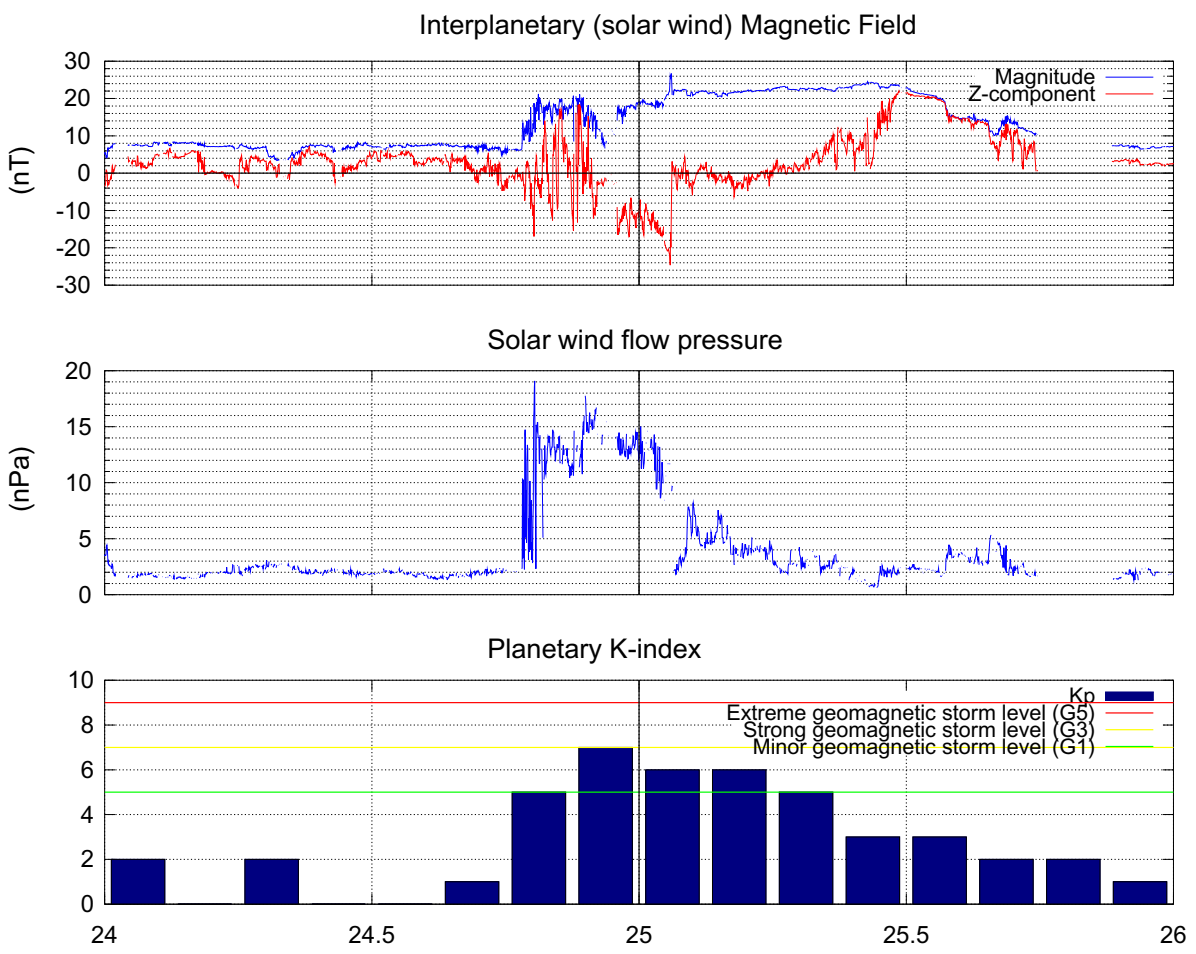

Time (Day of October 2011)

Fig. 2. The top panel shows solar wind magnetic field measurements. The middle panel shows the solar wind flow pressure. The solar wind data was obtained from the OMNI database and has been timeshifted $10 \mathrm{~min}$ to account for the propagation time from the bow shock to the ionosphere. The bottom panel shows the $K p$-index. Horizontal colored lines have been added to indicate the minimum, middle and maximum values of the NOAA space weather scale for geomagnetic storms (Poppe 2000). The vertical black line in the middle indicates midnight. 
Northern Norway (latitudes of 67 to 72 degrees North)

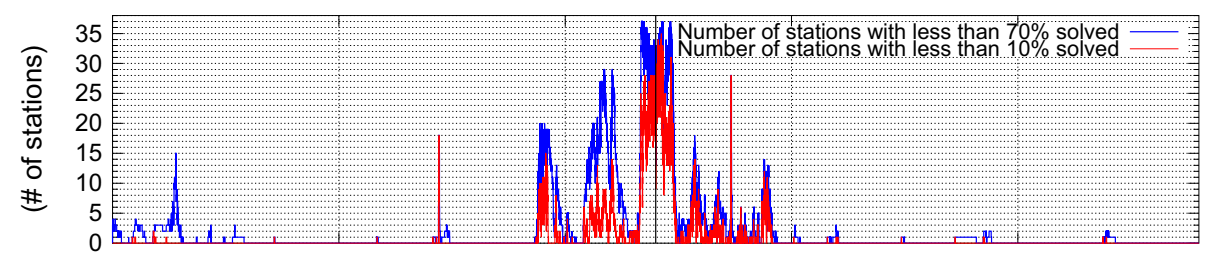

Middle Norway (latitudes of 62 to 67 degrees North)

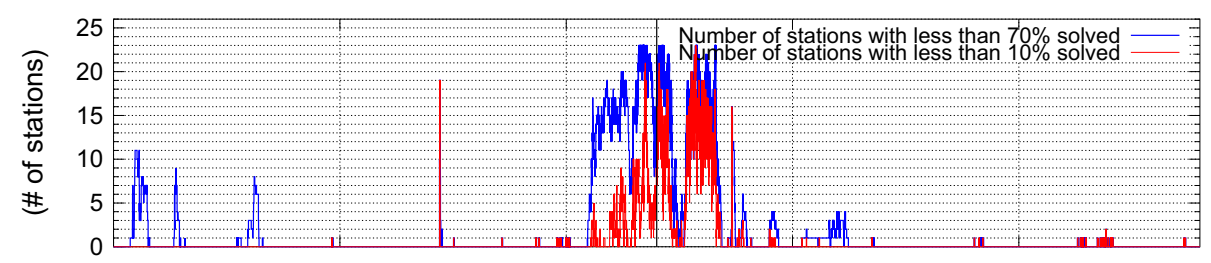

Southern Norway (latitudes of 57 to 62 degrees North)

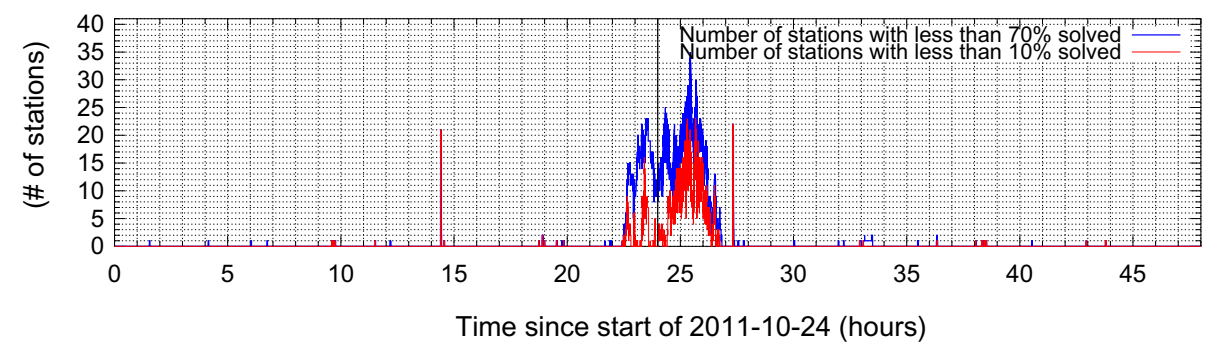

Fig. 3. The panels show the performance of the CPOS service, in the form of the number of stations that are unable to compute a solution for a percentage of the observed satellites. The percentage is $70 \%$ for the blue line and $10 \%$ for the red line. The top panel covers Northern Norway $\left(67-72^{\circ} \mathrm{N}\right)$, the middle panel covers middle Norway $\left(62-67^{\circ} \mathrm{N}\right)$ and the bottom panel covers Southern Norway $\left(57-62^{\circ} \mathrm{N}\right)$. The panels are scaled to the number of stations within each of regions, meaning that if the line reaches the top of a panel, $100 \%$ of the stations in that region are affected. The vertical black line in the middle indicates midnight.

An overview of the ionospheric activity observed by the ionosphere monitor is shown in Figure 4. The panels are organized in the same way as in Figure 3. The value plotted is the average ROTI observed by all stations in the region. A summary of the time series is as follows:

- At 18:45 UT, the ROTI for the northern region rises from a background level of $\sim 1$ to a level of 2-3 with spikes up to 4. A slight increase is seen in the ROTI for the middle region.

- At $20 \mathrm{UT}$, the ROTI of the northern region relaxes to a level of $\sim 2$.

- At 21 UT, the ROTI of both the northern and middle regions rise to a level of 2-3 with spikes up to 4 . A slight increase is seen in the southern region, with some spikes up to 3 .

- At 22:30 UT, there is a very sharp increase of ROTI in the northern and middle regions, rising to a level of 5-7. The ROTI of the southern region rises to a level of 2-4.

- At 01 UT on the 25th October, the ROTI of the northern region drops to a level of 2-4. The ROTI of the middle and southern regions lie at a level of 3-6.

- At 03 UT, the ROTI of the middle region drops to a level of 2-3 with spikes to 4 . The ROTI of the southern region drops to a level of $1-2$.

- At 05 UT, the ROTI of the middle and southern regions drops to the background level. The ROTI of the northern region stays slightly elevated at 1-2 for several hours before dropping to the background level.
An overview of the European Geostationary Navigation Overlay Service (EGNOS) (EGNOS website) performance during the storm days is shown in Figure 5. One day prior to and after the storm days have been included to show the performance during normal conditions. The time resolution of the EGNOS plots is one day. The plots show that EGNOS clearly suffered from service disruptions during the storm. The plots for the 24th October show disruptions mainly in the North, while the plots for 25th October show a disruption for the entire EGNOS area. This is consistent with the ionospheric disturbances shown in Figure 4, which indicate that for the southern latitudes, the main disturbances were seen on the 25 th.

Figure 6 shows the effects these disruptions would have on a user. The first panel is a measure of the ionospheric disturbances, the second panel is a measure of the RTK network disruptions and the last two panels are the error in position. The monitor station enjoys very good measurement conditions, as it is mounted on the roof of a building higher than the surrounding vegetation and other buildings, and is very close (10 s of meters) to one of the stations in the RTK network. Using the RTK corrections, it calculates its position every second in real time. The position error is measured by the 60 -s standard deviation of the vertical error. It has a normal value of less than $0.5 \mathrm{~cm}$. A summary of the time series is as follows:

- In the interval 17-21 UT, it experienced an increased error, peaking at $1.5 \mathrm{~cm}$. At this time, the RTK network is operating at normal, but there may be some less severe noise resulting from the ionospheric disturbances. 
K.S. Jacobsen and S. Schäfer: Geomagnetic storm effects on an RTK network

Northern Norway (latitudes of 67 to 72 degrees North)

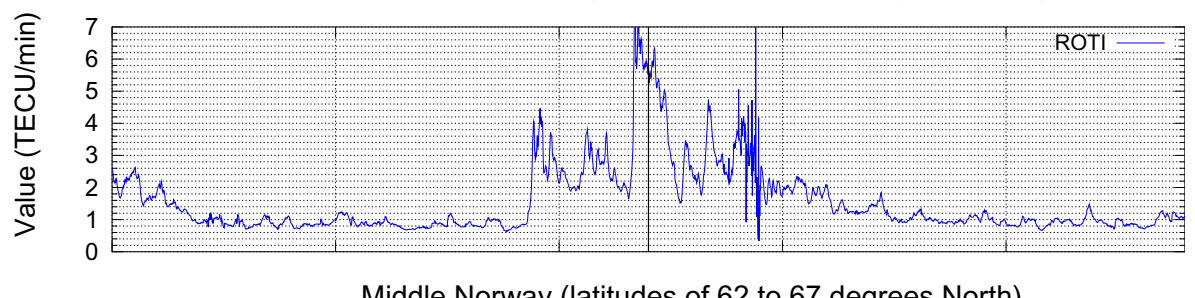

Middle Norway (latitudes of 62 to 67 degrees North)

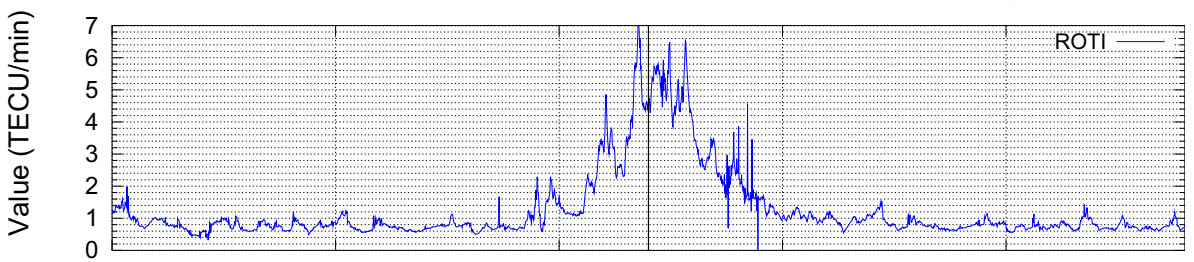

Southern Norway (latitudes of 57 to 62 degrees North)

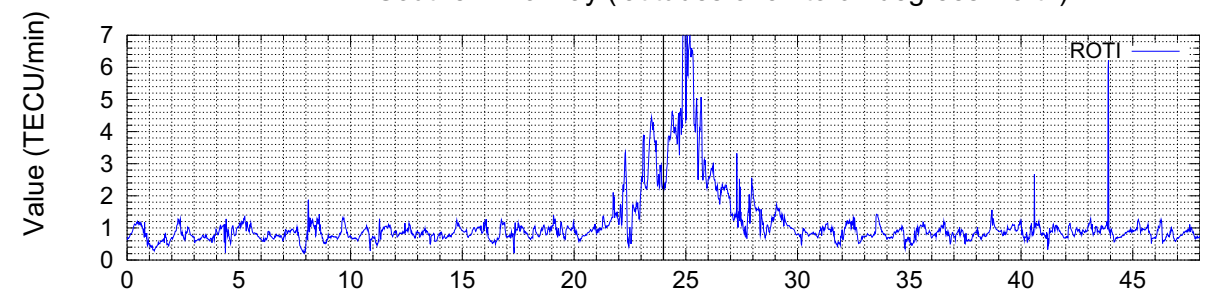

Time since start of data (hours)

Fig. 4. The panels show the ionospheric disturbances, measured by the ROTI. For each region, this shows the average ROTI observed by all stations in that region. The top panel covers Northern Norway $\left(67-72^{\circ} \mathrm{N}\right)$, the middle panel covers middle Norway $\left(62-67^{\circ} \mathrm{N}\right)$ and the bottom panel covers Southern Norway $\left(57-62^{\circ} \mathrm{N}\right)$. The vertical black line in the middle indicates midnight.

\section{EGNOS performance}

The time period shown in the other figures

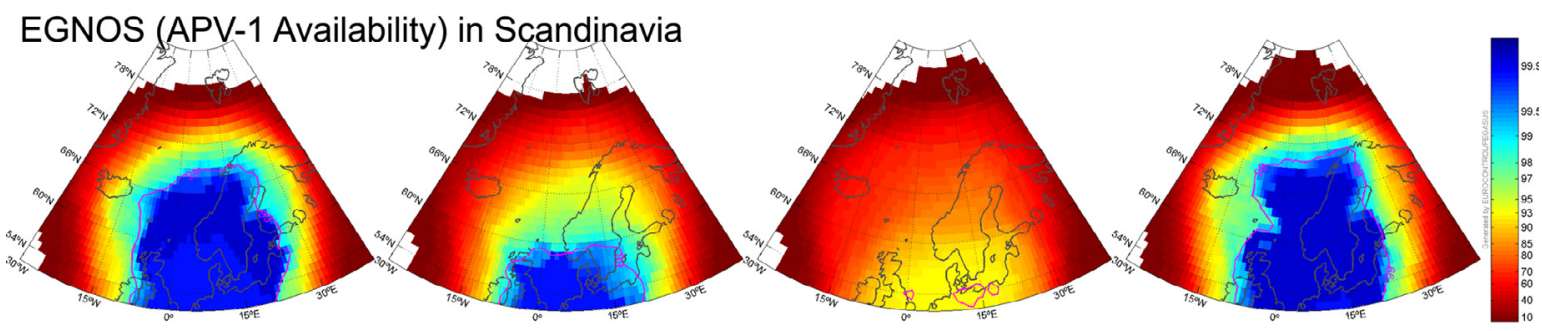

EGNOS (APV-1 Availability) in Europe

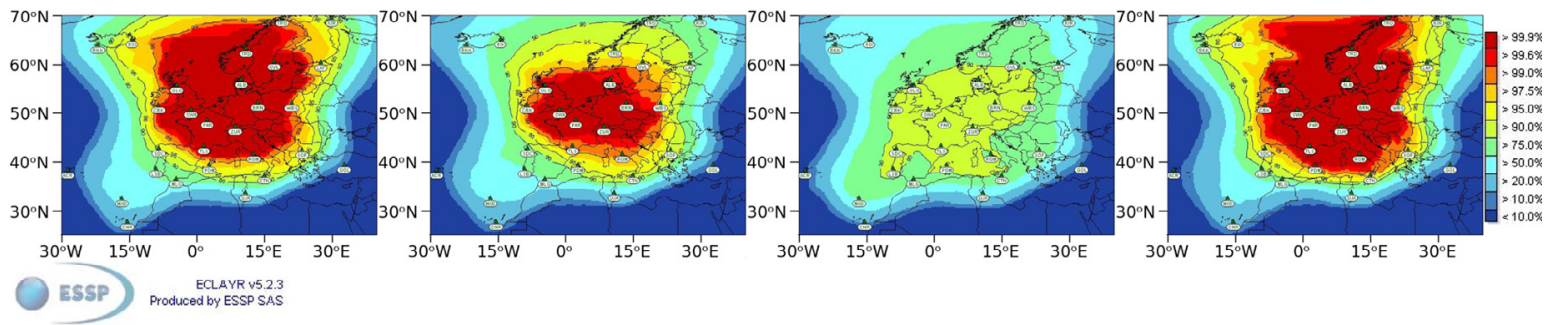

Fig. 5. EGNOS performance during the event. The top row of plots shows the APV-1 (EGNOS-SoL-SSD) availability in the Scandinavian region, with light blue indicating $99 \%$ availability and dark blue indicating $99.9 \%$. The bottom row of plots shows the APV-1 availability in the European region, with orange indicating $99 \%$ availability and dark red indicating $99.9 \%$. 

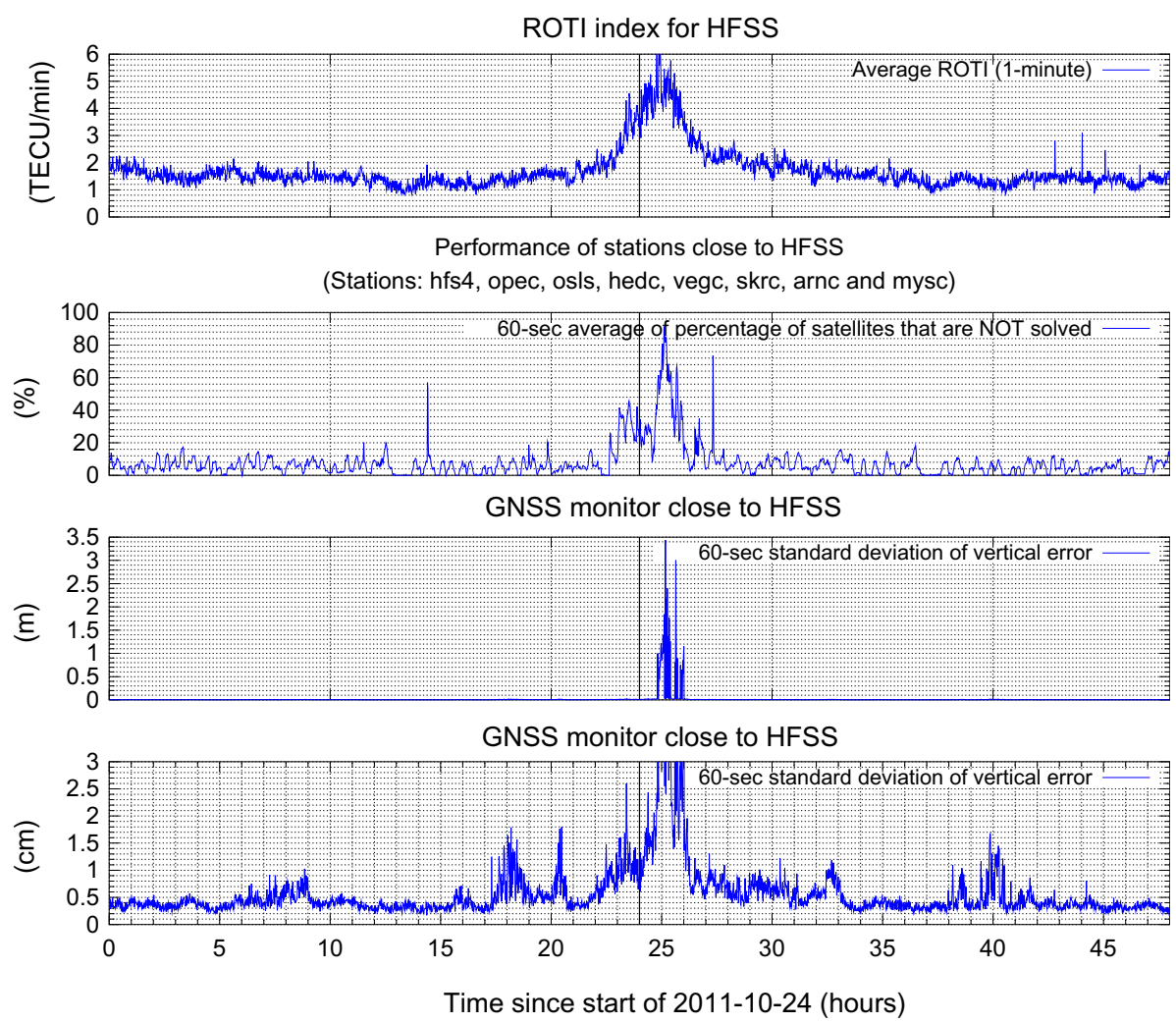

Fig. 6. The first panel shows the ROTI for Hønefoss station. The second panel shows the performance of stations within $100 \mathrm{~km}$ of Hønefoss, in the form of the percentage of observed satellites for which the software cannot find a solution. The third and fourth panels show the standard deviation of the vertical position error, using respectively a meter and centimeter scale in order to show the entire range of values. The vertical black line in the middle indicates midnight.

- At 22:30 UT, the RTK network itself is disrupted, but the error experienced by the monitor is the same as for the previous interval. This coincides with an increasing ROTI.

- At 01 UT on the 25th October, the RTK network disruption increases suddenly, peaking at $90 \%$. This means that the network close to the monitor station is unable to supply corrections with fixed ambiguities for $90 \%$ of the currently visible satellites. This coincides with the peak of the ROTI. At this time the position error increases several orders of magnitude, peaking at $3 \mathrm{~m}$. This condition lasts for about $1 \mathrm{~h}$.

It should be noted that this monitor station was located in the southern part of Norway. Users further North would have experienced more, longer, and more severe disruptions of the positioning service.

Figure 7 shows measurements of phase scintillation, by a scintillation receiver in the same location as the monitor station. Scintillation is observed from 22 UT on the 24th to 04 UT on the 25th, matching the duration and shape of the ROTI graph for the Hønefoss station (first panel of Fig. 6).

Figures 8-11 show examples of the status of CPOS and the ionosphere at four different times during the night.

- At 22:05 UT (Fig. 8) a roughly longitudinal band of enhanced TEC and large ROTI is clearly seen between $60^{\circ}$ and $70^{\circ} \mathrm{N}$. Receivers located at latitudes from $64^{\circ}$ to $70^{\circ} \mathrm{N}$ experience severe disturbances. There had been some activity prior to this time but from this time onwards the disturbances are more severe, and there are very clear signatures of roughly longitudinal bands of enhanced

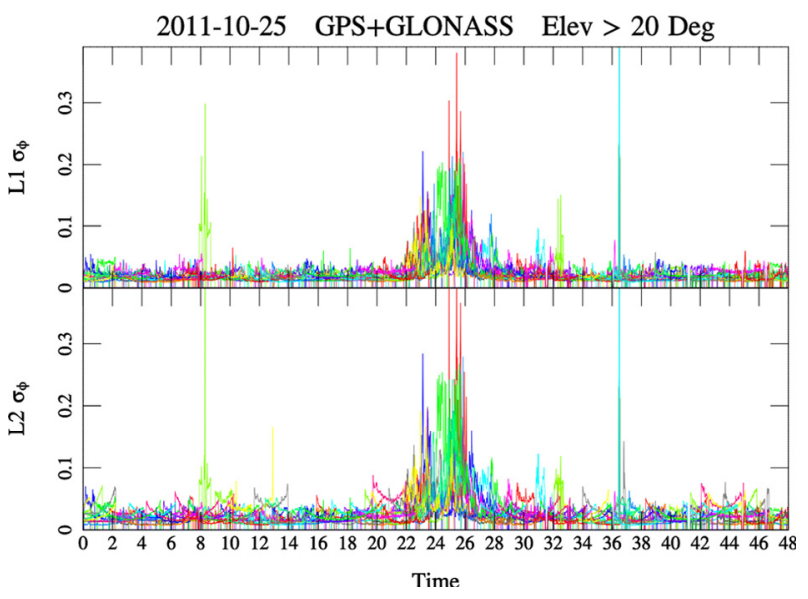

Fig. 7. The top panel shows the phase scintillation index $\sigma_{\phi}$ for the L1 frequency. Each colored line is a separate satellite. The bottom panel shows the same for the L2 frequency.

TEC and small-scale structuring. This is consistent with being caused by particle precipitation in the auroral oval.

- At 23:00 UT (Fig. 9) the band has moved south to latitudes of $57^{\circ}-65^{\circ}$ N. Disturbances are seen by receivers at latitudes of $61^{\circ}-66^{\circ} \mathrm{N}$. As seen in two, the Z-component of the solar wind magnetic field has been negative for a while at this time, which causes the auroral oval to expand equatorward.

- At 23:30 UT (Fig. 10) the disturbed region has expanded significantly, covering latitudes of $56^{\circ}-75^{\circ} \mathrm{N}$ and practically disabling the CPOS service at all latitudes 


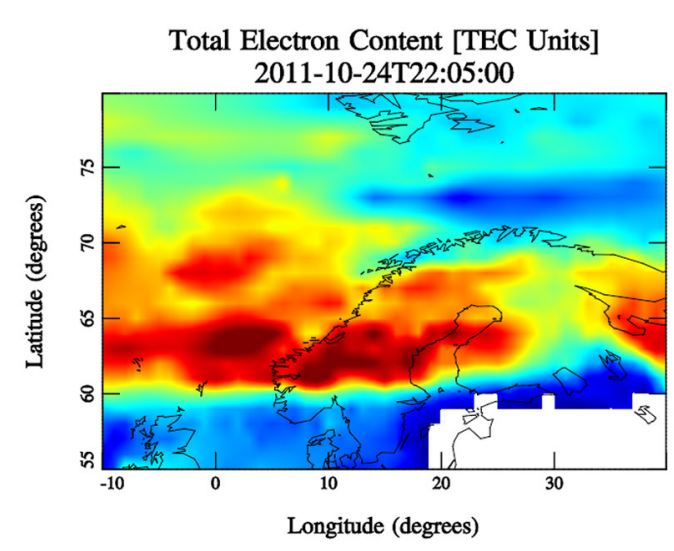

Mean ROTI observed at ground locations [TECU/min] 2011-10-24T22:05:00

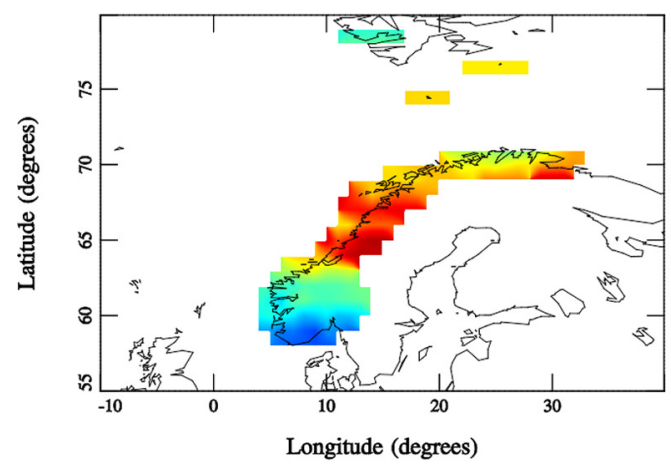

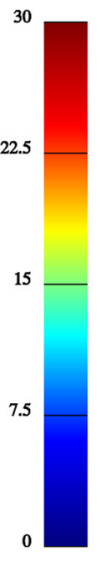

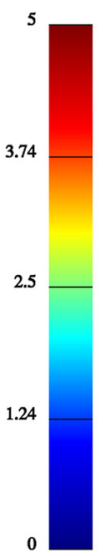

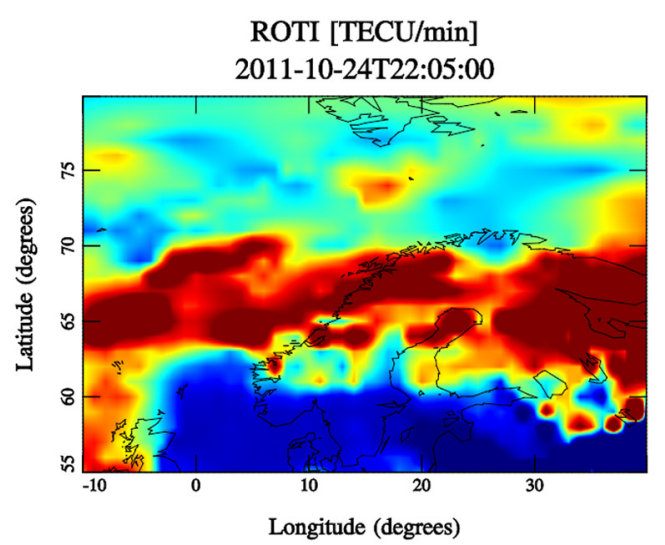

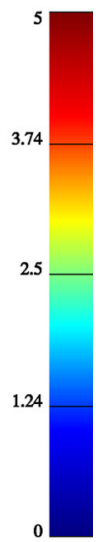

CPOS station performance

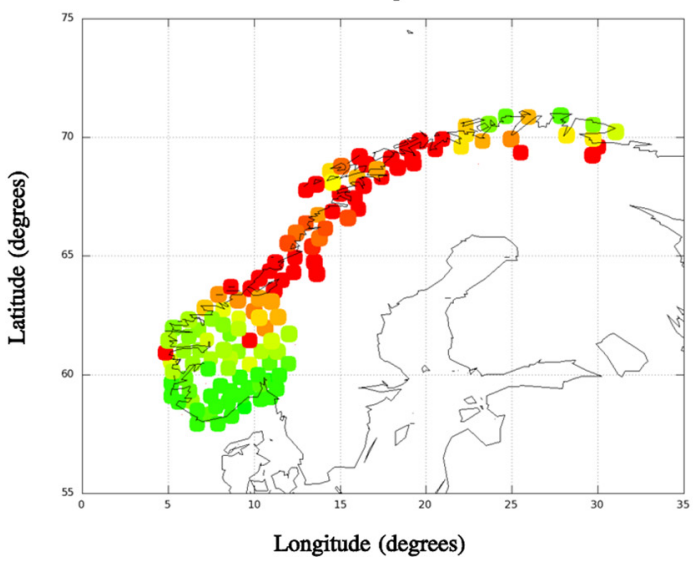

Fig. 8. The status of CPOS and the ionosphere at 22:05 UT on 24th October. Upper left: from RTIM: vertical total electron content, assuming an ionosphere layer at $350 \mathrm{~km}$ altitude. Upper right: from RTIM: ROTI in the ionosphere, assuming an ionosphere layer at $350 \mathrm{~km}$ altitude. Lower left: from RTIM: the average ROTI observed by ground receivers. Lower right: from CPOS: the ratio of solved satellites versus tracked satellites, where pure green is $100 \%$ solved, pure yellow is $70 \%$ solved and pure red is $0 \%$ solved. The scale is linear between each color. There is one colored circle per station, and the size of the circle is proportional to the number of tracked satellites, so there will be no symbol drawn for a station which does not track any satellites.

above $60^{\circ} \mathrm{N}$. This was the greatest extent of disturbances that was seen during the storm.

- At 01:20 UT (Fig. 11) the disturbed region lies at latitudes of $57^{\circ}-65^{\circ} \mathrm{N}$. Severe disruption of the CPOS service is seen between latitudes of $60^{\circ}$ and $65^{\circ} \mathrm{N}$. This is one of the last times for which the disturbances show a very clear shape. As seen in Figure 2, the magnetic field Z-component starts to fluctuate around zero shortly after this, making for a more complicated solar wind-magnetosphereionosphere interaction. Less organized disturbances can be seen for several hours.

Figure 12 shows the results of an operational forecasting auroral oval model (Sigernes et al. 2011) for the same times as seen in the four previous Figures 8-11. The model provides an estimate of the auroral oval location and extent, based on auroral oval statistical records parameterized by time of day and $K p$. The model results shown here are not the forecasted results, but results based on the actually measured $K p$ values. For the three first times, the auroral oval model is very similar. This is to be expected, as they lie within a 90-minute interval and the $K p$ index is the same. Comparing the model to the ionosphere measurements in the previous figures, the ionospheric disturbances are located within the region indicated by the model, but the exact location, extent and activity level varies significantly. This variation is not captured by the model. For 01:20 UT, the observed activity lies southward of the green band seen in the model plot. The model would have been more similar to the observations if it had used a larger $K p$ value at this time.

Figure 13 shows measurements of the auroral electrojet, based on data from the IMAGE network of magnetometers, processed by a $2 \mathrm{D}$ equivalent current model (Amm \& Viljanen 1999). The data shown in the figure are meridional slices from the $2 \mathrm{D}$ model. When comparing this figure to the others, keep in mind that the time scale of this figure does not cover the entire two days, but only $6 \mathrm{~h}$ prior to and after midnight. A summary of the features seen in the figure:

- At 19 UT, a strong current is seen at around $75^{\circ} \mathrm{N}$. The current gradually expands southward to $70^{\circ} \mathrm{N}$. The peak integrated current reaches almost $1 \mathrm{MA}$.

- At 20 UT, the current weakens. It reaches the background level within roughly half an hour.

- At $23 \mathrm{UT}$, a strong current appears at $65^{\circ} \mathrm{N}$. The current region expands rapidly northward until it covers an area from $62^{\circ}$ to $80^{\circ} \mathrm{N}$. The total current of the electrojet also increases rapidly, exceeding 2.5 MA around 23:30 UT and staying at that level for $45 \mathrm{~min}$. Peak current was 2.8 MA. This peak current makes this about the 20th largest event in the period of 1994-2011 in the IMAGE region.

- After 24 UT the electroject moves southward while shrinking both in coverage and in total current. Strong currents are seen as far southward as $60^{\circ} \mathrm{N}$. 


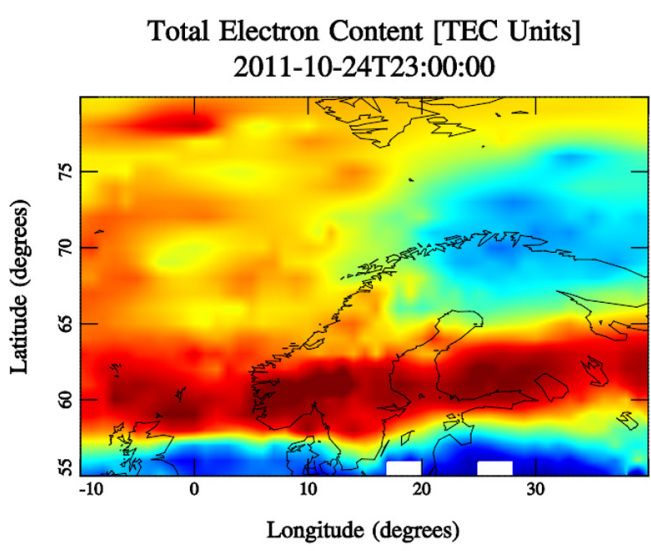

Mean ROTI observed at ground locations [TECU/min] 2011-10-24T23:00:00

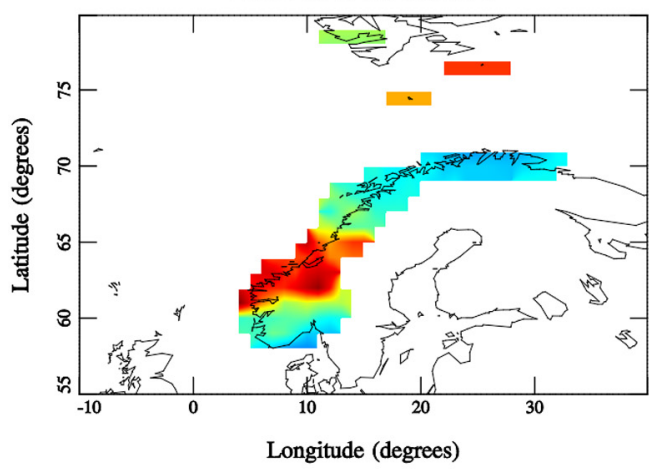

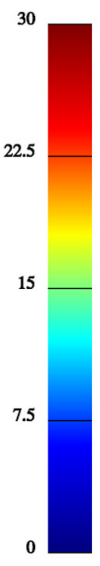

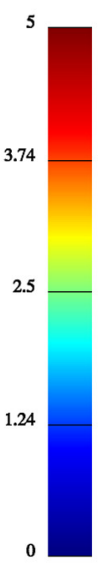

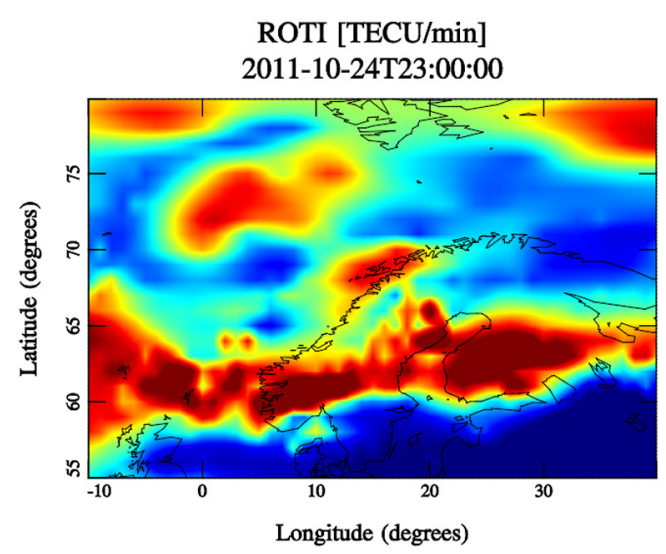

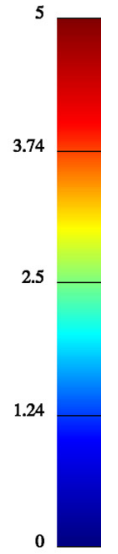

CPOS station performance

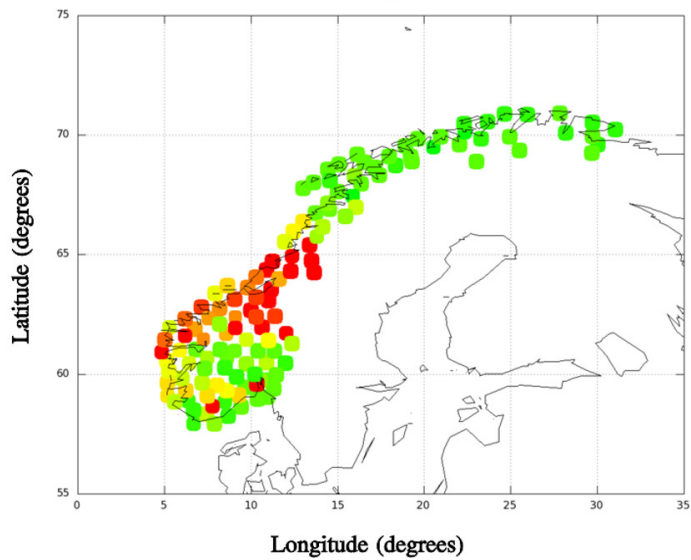

Fig. 9. The status of CPOS and the ionosphere at 23:00 UT on 24th October. The panels are described in the caption of Figure 8.

- At 01 UT on the 25th October, the electrojet starts to move northward, while still shrinking in coverage and total current.

- At 03:45 UT, after having vanished for a short while, the electrojet reactivates, at around $70^{\circ} \mathrm{N}$. It rises to a peak total current of $1 \mathrm{MA}$, then slowly decays over the course of an hour.

\section{Discussion}

The following is a summary of our interpretation of the events presented in this paper. In the evening of the 24th of October, a CME impacted Earth's magnetosphere. As the effects of this reached the ionosphere, ionospheric disturbances appeared in the auroral zone. The magnetic field of the first part of the CME was very turbulent and did not cause a large expansion of the auroral oval. Disruptions of the CPOS service were seen mostly in the northern part of Norway, above $67^{\circ} \mathrm{N}$. At 22 UT the magnetic field became more stable, with a negative $Z$-component, and between 23 UT and 01:30 UT the following day the $Z$-component was between -10 and $-20 \mathrm{nT}$. This caused the auroral oval to expand, and the effects of the geomagnetic storm were felt at lower latitudes. The particle precipitation in the auroral oval caused greatly enhanced VTEC and ROTI values, and for the period where the magnetic field was steady with a strongly negative $Z$-component, the enhancements formed roughly longitudinal bands, consistent with the shape of the auroral oval. Between 23 UT on the 24th and 01 UT on the 25th, nearly all stations in Northern Norway were practically disabled. Around 01 UT, the effects of these disturbances for a CPOS user could be seen in the data from a monitor station in Hønefoss. As the network RTK software failed to correct for the ionospheric activity, the monitor station received no corrections and its position error increased by several orders of magnitude. The largest user groups of the CPOS system are construction companies and private and governmental surveyors. One way in which CPOS is used by construction companies is to guide the operators of heavy machinery, such as excavators. These users depend on CPOS to deliver a certain degree of accuracy. During the disturbances seen in this event, the system would be unusable at best. At worst, an automatic system or careless user could make costly mistakes if they used the service under these conditions. As a consequence of the greatly expanded auroral oval, between 01 and 03 UT the CPOS service was severely disrupted in middle and Southern Norway, but only mildly disrupted in Northern Norway. The evolution of the disturbances, in particular the evolution of the affected latitudes, could not have been forecasted based on GNSS data alone, as the evolution of the auroral oval is mainly controlled by the incoming solar wind.

To quantify the effects of the ionospheric disturbances on the positioning accuracy, the 60-s standard deviation of the vertical and horizontal coordinates was binned by ROTI and then averaged. The results are shown in Figure 14. The error increases exponentially with increasing ROTI values. At ROTI greater than three, the error is significantly greater than any local error source. It is noted that as this is the average level of the standard deviation of the position error, individual positions can have a far greater error. This graph shows that small-scale structuring 


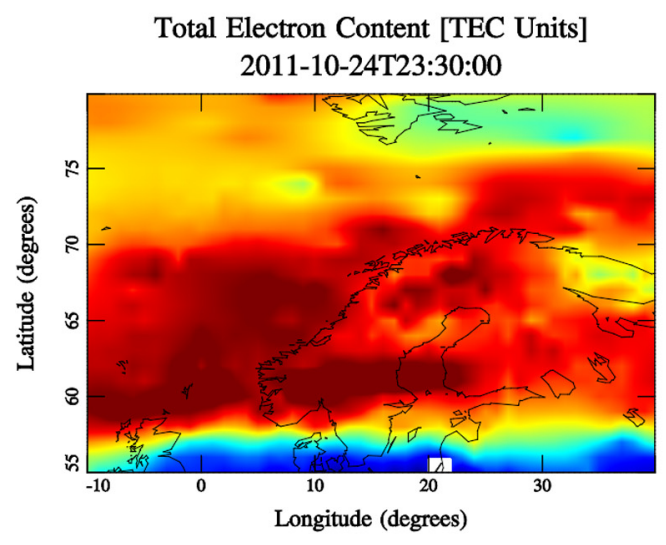

Mean ROTI observed at ground locations [TECU/min] 2011-10-24T23:30:00

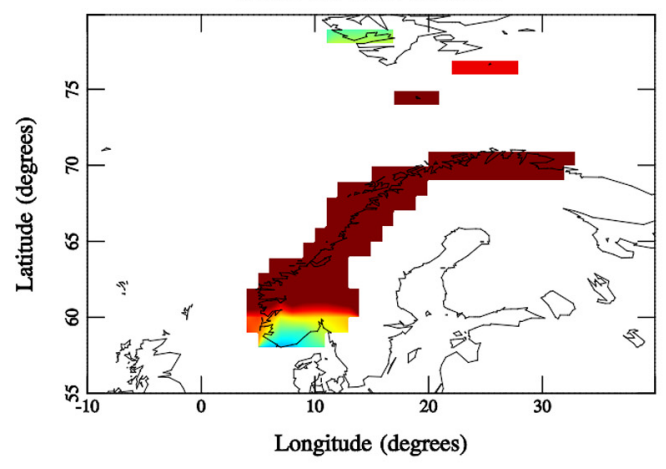

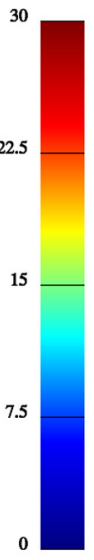

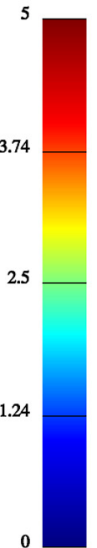

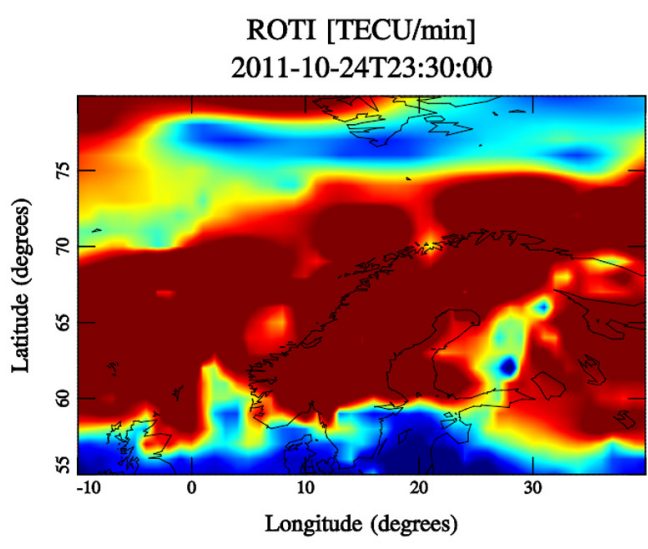

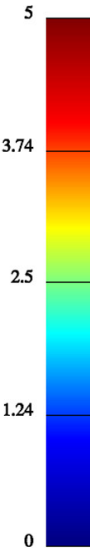

CPOS station performance

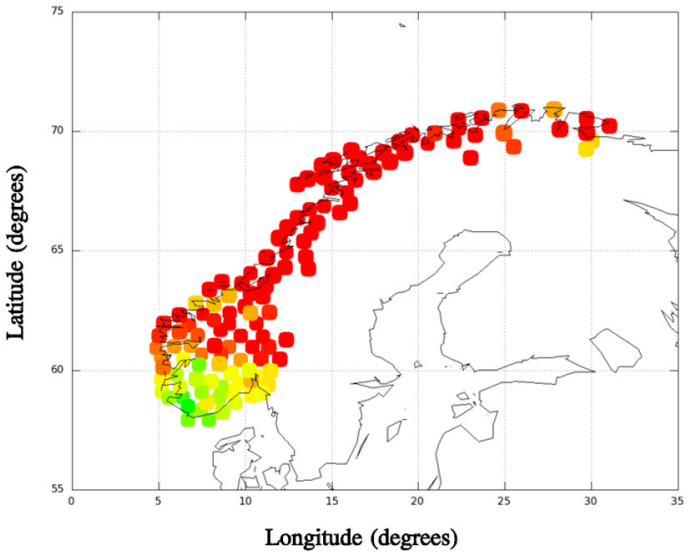

Fig. 10. The status of CPOS and the ionosphere at 23:30 UT on 24th October. The panels are described in the caption of Figure 8.

of the ionospheric plasma has a detrimental effect on the final coordinates computed in an RTK system, even for low levels of activity. As the ionospheric activity increases, the effect grows exponentially and at high levels of ionospheric activity it becomes greater than any other error source.

The results of an operational forecasting auroral oval model have been presented and compared to the results of the ionosphere monitoring software. While the model appears to give a good indication of the approximate range of latitudes affected, and the strength of the auroral oval activity, it cannot model the variations that are observed. This is to be expected, since it is an empirical model parameterized by time of day and the $K p$ index. For users of GNSS systems such as CPOS, the model could be useful as a first warning that problems may occur in a region. Its performance is limited by the availability of reliable $K p$ forecasts.

Measurements of the auroral electrojet were presented (Fig. 13). A peak current of $2.8 \mathrm{MA}$ makes it about the 20th largest event in the period of 1994-2011 in the IMAGE region, and strong currents were seen as far south as $60^{\circ} \mathrm{N}$. Comparing the currents to the CPOS disruptions (Fig. 3) and the ionospheric activity (Fig. 4), the following is noted:

- The first period of strong currents, occurring at 19-20 UT and located between $70^{\circ}$ and $80^{\circ} \mathrm{N}$, coincides with the first period of disturbances in the northern region.

- The disturbances that start at 21 UT do not coincide with any strong currents.

- The second period of strong currents, starting some time before $23 \mathrm{UT}$ and growing rapidly after $23 \mathrm{UT}$, coincides with the third period of disturbances. As the currents expand to high latitudes around 24 UT, the disturbances in the northern region reach their peak. The disturbances in the southern region peak at the same time as the currents are at their lowest latitude $\left(\approx 60^{\circ} \mathrm{N}\right)$. At this time, the monitor station at Hønefoss (at $\approx 60^{\circ} \mathrm{N}$ ) records large positioning errors (Fig. 6) and the scintillation receiver detects scintillation (Fig. 7).

- The third period of strong currents, starting at 03:45 UT, coincides with a slight increase in the ROTI for the middle and northern regions.

- The end of the strong currents, at 05 UT, coincides with the end of the CPOS disruptions.

Except for the second period of disturbances, the auroral electrojet measurements agree with the other data regarding the timing of the activity and the regions affected. Comparing the currents to the snapshots of the ionosphere state (Figs. 8-11), the following is noted:

- For the purposes of comparing to the currents, the latitude ranges given here are for the ROTI plots, not the TEC plots, and for a longitude of $22^{\circ}$ E. This means that they are a little different from the latitudes given in the earlier description of these plots, as those encompassed both the enhanced TEC and ROTI, and all longitudes.

- At 22:05 UT, the ionospheric plots indicate activity at latitudes of $62-70^{\circ} \mathrm{N}$. There are no strong electrojet currents at this time, but there are some signs of smaller currents in the vicinity of $65^{\circ} \mathrm{N}$.

- At 23 UT, the ionospheric plots indicate activity at latitudes of $60-65^{\circ} \mathrm{N}$. Strong currents are observed at latitudes of $60-65^{\circ} \mathrm{N}$. 
J. Space Weather Space Clim. 2 (2012) A13
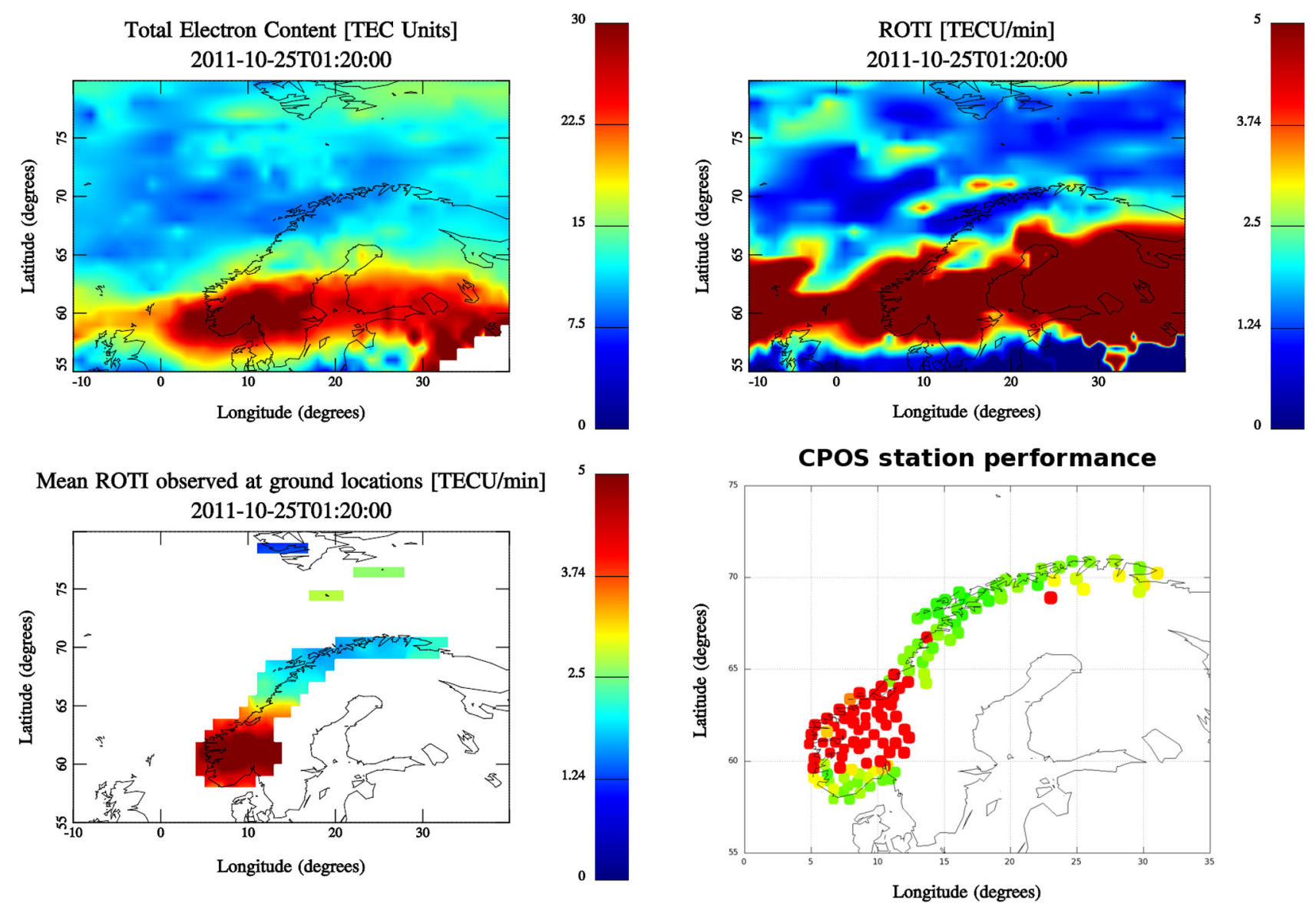

Fig. 11. The status of CPOS and the ionosphere at 01:20 UT on 25th October. The panels are described in the caption of Figure 8.

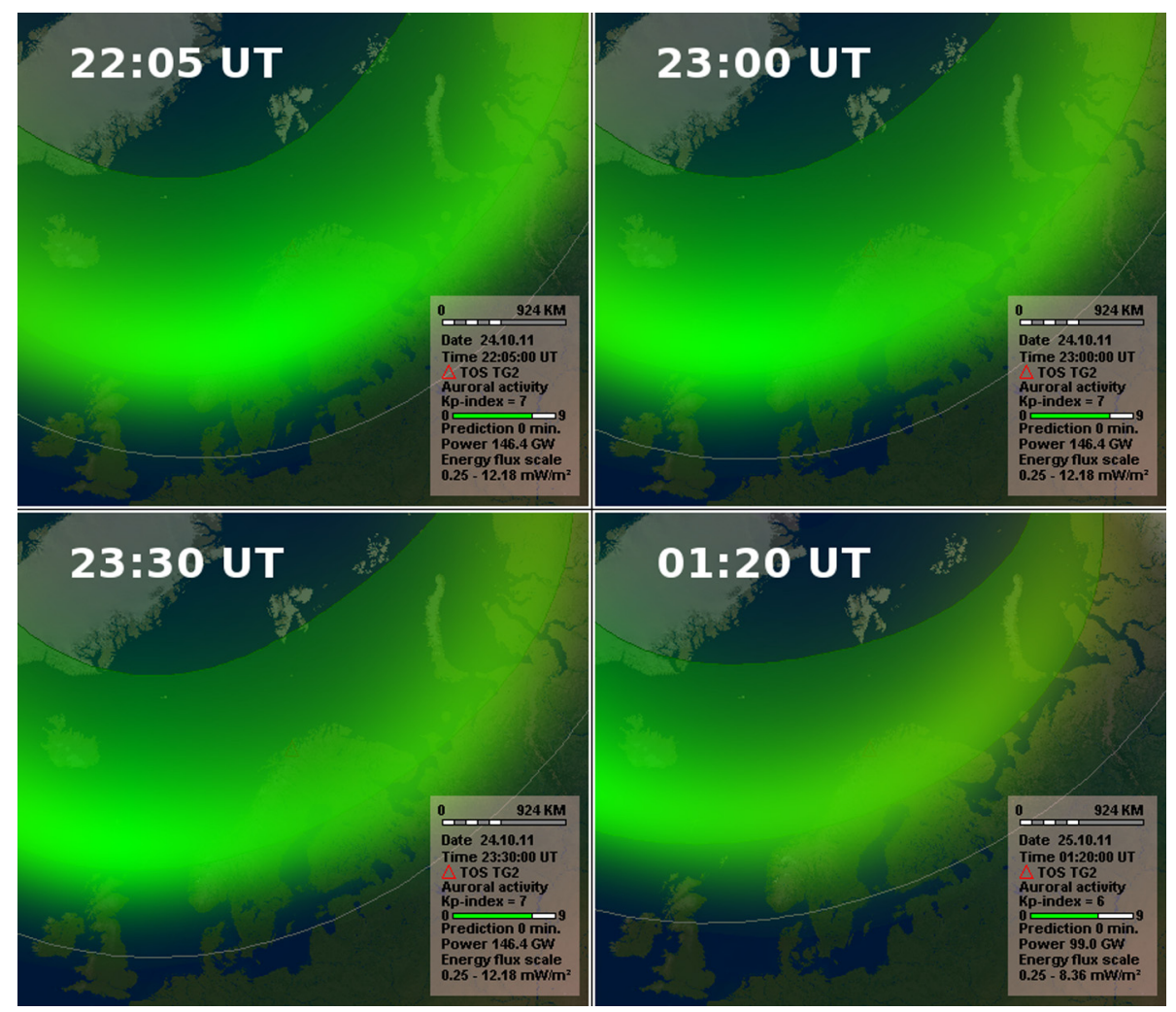

Fig. 12. Results from an empirical model (Sigernes et al. 2011) of the location and extent of the auroral oval for the times shown in Figures $8-11$. 

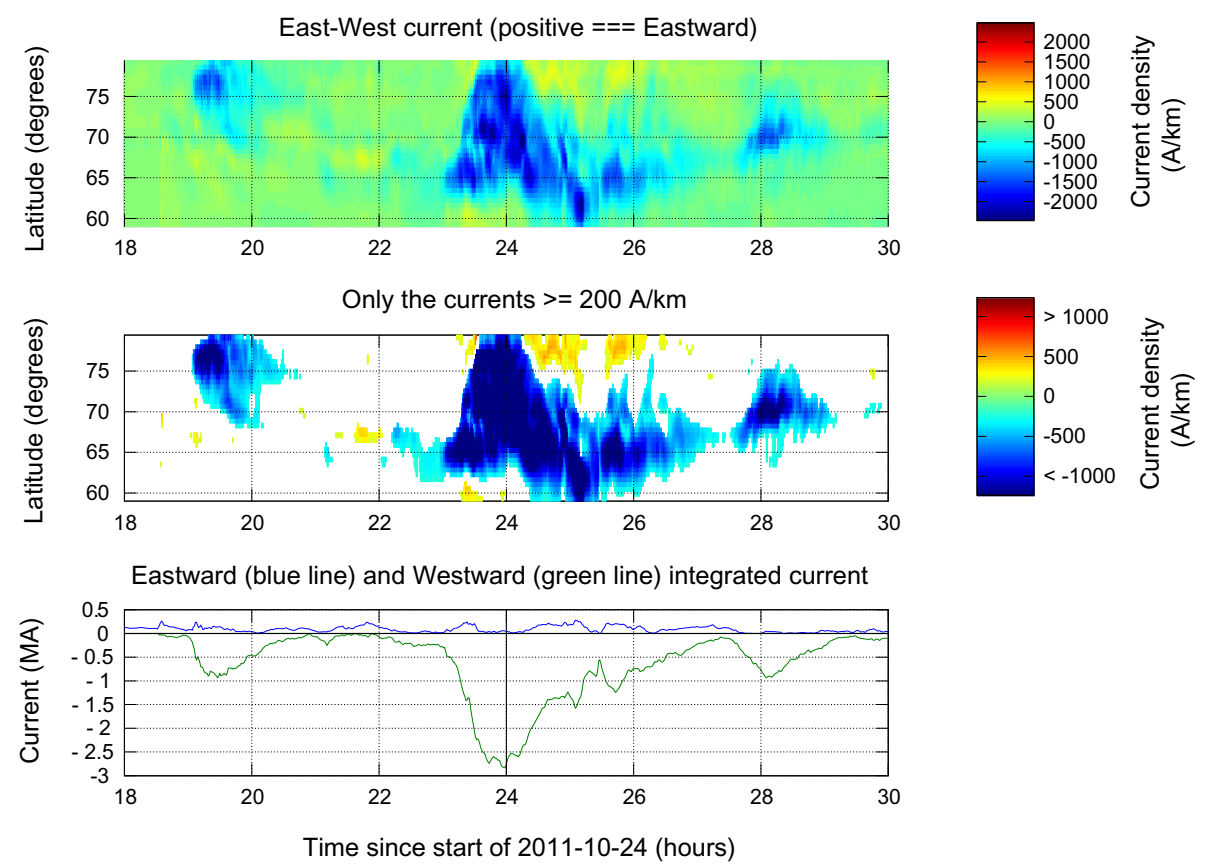

Fig. 13. Measurements of the auroral electrojet, based on data from the IMAGE magnetometer network (Amm \& Viljanen 1999). The top panel shows the current as a function of time and latitude. The longitude is constant at $22^{\circ} \mathrm{E}$. The middle panel emphasizes strong currents by showing only current densities exceeding $200 \mathrm{~A} / \mathrm{km}$, and using a different color scale. The bottom panel shows the total eastward and westward electrojet currents, integrated over all latitudes.

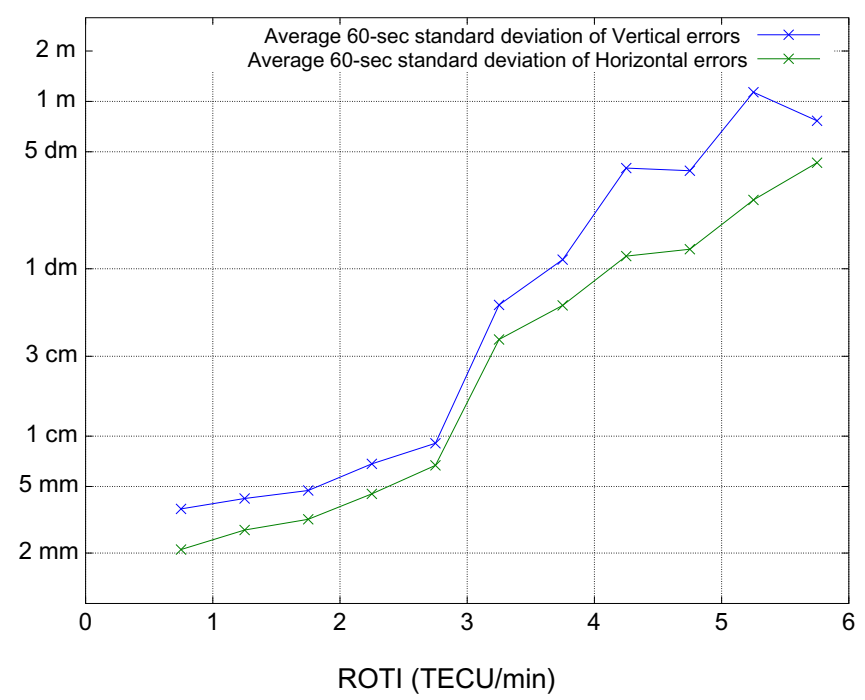

Fig. 14. This is a scatter plot of the average position errors as a function of ROTI, based on all the data from the two days investigated in this paper. The data has been binned by ROTI with a bin size of 0.5 ROTI. The crosses mark the center of each ROTI bin. Vertical position errors are indicated by the blue line, while horizontal position errors are indicated by the green line.

- At 23:30 UT, the ionospheric plots indicate activity at latitudes of $60-75^{\circ} \mathrm{N}$. Strong currents are observed at latitudes of $62-75^{\circ} \mathrm{N}$.

- At 01:20 UT on the 25th, the ionospheric plots indicate activity at latitudes of $59-68^{\circ} \mathrm{N}$. Strong currents are observed at latitudes of $59-70^{\circ} \mathrm{N}$.

Except for the plot for 22:05 UT, the observed currents indicated activity at the same latitude ranges as the ROTI. The comparisons suggest that a forecast of the auroral electrojet would be a very valuable contribution to a forecast of GNSS disturbances. It is noted that there are currently efforts underway to provide auroral electrojet forecasts (Wang et al. 2008).

This geomagnetic storm reached a level of G3 on the NOAA space weather scale for geomagnetic storms. NOAA expects an average of 200 storms of this strength during one solar cycle (Poppe 2000), which means that this is a fairly normal occurrence that we must expect and be prepared for. The disruptions can be fairly localized, covering a range of latitudes while leaving other latitudes unaffected. Which regions are affected depends on the solar wind-magnetosphere-ionosphere interactions. The disruptions may last for considerable amounts of time. In the case presented here, the disruptions in Northern Norway lasted more than $10 \mathrm{~h}$, with varying intensity. During this period, the CPOS service was unreliable at best, and disabled or potentially misleading at worst. The fact that the case presented here took place outside of normal working hours limited its practical impact. The exact level of disturbances of the GNSS services is strongly dependent upon the time of day for which the storm occurs, as the auroral oval is positioned differently and reacts differently for different time sectors. One topic of future work will be to examine the effects of a geomagnetic storm of this magnitude during the middle of the day.

\section{Conclusions}

- Ionospheric activity in the auroral oval zone greatly disturbs GNSS systems. When affected by strong ionospheric activity, accurate systems such as CPOS become unusable.

- The ROTI is a good measure of the disturbance level. The position error increases exponentially with increasing ROTI.

- The disruptions can be fairly localized, covering a range of latitudes while leaving other latitudes unaffected. 
- The auroral oval forecasting model currently available at http://kho.unis.no/Forecast.htm can provide a first warning of disturbances, but its spatial and temporal resolution is coarse.

- The disturbances are strongly related to auroral electrojet currents. A forecast of the auroral electrojet would be a very valuable contribution to a forecast of GNSS disturbances. It is noted that there are currently efforts underway to provide auroral electrojet forecasts (Wang et al. 2008).

Acknowledgements. The authors thank the reviewers and the editor for their helpful comments. The solar wind data were obtained from the GSFC/SPDF OMNIWeb interface at http://omniweb.gsfc. nasa.gov. The $K$ indices were obtained from NOAA, Space Weather Prediction Center. Plots of APV-1 availability in the European region were obtained from the ESSP-SAS website at http://www.essp-sas.eu. Figure 1 was created using the Google Earth software, using data from Google and its data providers, which are listed in the figure itself. Data for the auroral electrojet was obtained from the IMAGE magnetometer network (http://space.fmi.fi/image/). The authors thank Ari Viljanen of the Finnish Meteorological Institute for his comments and help in processing the IMAGE magnetometer data. The authors thank Fred Sigernes of the University Centre in Svalbard for providing results from the auroral oval forecasting model.

\section{References}

Amm, O., and A. Viljanen, Ionospheric disturbance magnetic field continuation from the ground to the ionosphere using spherical elementary current systems, Earth, Planets Space, 51, 431-440, 1999.

Aquino, M. et al., Ionospheric scintillation and impact on GNSS users in Northern Europe: results of a 3 year study, Space Commun., 2005.

Basu, S. et al., A comparison of TEC fluctuations and scintillations at Ascension Island, J. Atm. Solar-Terr. Phys., 61, 1219-1226, 1999.

Buonsanto, M.J., Ionospheric storms - a review, Space Sci. Rev., 88, 563-601, 1999.

Eastwood, J.P., The science of space weather, Philos. Trans. R. Soc., 366, 4489-4500, 2008
EGNOS Safety of Life Service Definition Document, Ref: EGN-SSD SoL, V1.0. http://www.egnos-pro.esa.int/index.html

Frodge, S.L. et al., Real-time on-the-fly kinematic GPS system results, Navigation, 41 (2), 175-186, 1994.

Gonzalez, W.D., E. Echer, B.T. Tsurutani, A.L. Clua de Gonzalez, and A. Dal Lago, Interplanetary origin of intense, superintense and extreme geomagnetic storms, Space Sci. Rev., 158, 69-89, 2011.

Hernandez-Pajares, M., J.M. Juan, J. Sanz, A. Aragn-ngel, A. Garca-Rigo, D. Salazar, and M. Escudero, The ionosphere: effects, GPS modeling and the benefits for space geodetic techniques, J. Geodesy, 85, 887, 2011.

Kintner, P.M., B.M. Ledvina, and E.R. de Paula, GPS and ionospheric scintillations, Space Weather, 5, S09003, 2007.

$\mathrm{Pi}$, X. et al., Monitoring of global ionospheric irregularities using the worldwide GPS network, J. Atm. Solar-Terr. Phys., 24 (18), 2283-2286, 1997.

Poppe, B.B., New scales help public, technicians understand space weather, Eos Trans. AGU, 81 (29), 322, 2000.

Rizos, C., Network RTK research and implementation - a geodetic perspective, J. Global Positioning Syst., 1 (2), 144-150, 2003.

Sigernes, F., M. Dyrland, P. Brekke, S. Chernouss, D.A. Lorentzen, K. Oksavik, and C.S. Deehr, Two methods to forecast auroral displays, J. Space Weather Space Clim., 1, A03, 2011.

Singh, A.K., D. Siingh, and R.P. Singh, Space weather: Physics, effects and predictability, Surv. Geophys., 31, 581, 2010.

Skone, S. et al., Characterizing ionospheric irregularities for auroral scintillations, Proceedings of ION GNSS, 2009.

Tiwari, R. et al., Investigation of high latitude ionospheric scintillation observed in the Vanadian region, Proceedings of ION GNSS, 2010.

Wang, H., H. Luehr, A. Ridley, P. Ritter, and Y. Yu, Storm time dynamics of auroral electrojets: CHAMP observation and the space weather modeling framework comparison, Ann. Geophysicae, 26, 555-570, 2008.

Watermann, J., R. Vainio, J. Lilensten, A. Belehaki, and M. Messerotti, The state of space weather scientific modeling - an introduction, Space Sci. Rev., 147, 111-120, 2009.

Yeh, K.C., and C.-H. Liu, Radio wave scintillations in the ionosphere, Proc. IEEE, 70, 324, 1982. 